\title{
Low-flow Sevoflurane Anesthesia in Laparoscopic Cholecystectomy
}

\author{
Department of Anesthesiology and Pain Medicine, School of Medicine, Keimyung University, Daegu, Korea
}

Young Ho Jang, M.D., and Sue Rung Oh, M.D.

Background: Anesthetists participating in laparoscopic cholecystectomy (LC) with $\mathrm{CO}_{2}$ pneumoperitoneum has been cautious about adapting low-flow anesthesia (LFA). We investigated the efficacy of LFA compared to high-flow anesthesia (HFA) in LC.

Methods: Eighty patients undergoing LC were randomly assigned to one of the two groups $(\mathrm{n}=40$ each). In LFA, $1 \mathrm{~L} / \mathrm{min}$ $\left(50 \% \mathrm{O}_{2}\right.$ and $\left.\mathrm{N}_{2} \mathrm{O}\right)$ of the total fresh gas flow (FGF) was used, whereas $4 \mathrm{~L} / \mathrm{min}$ of the total FGF was used for HFA. Inspiratory and expiratory concentrations of $\mathrm{O}_{2}, \mathrm{~N}_{2} \mathrm{O}, \mathrm{CO}_{2}$, and sevoflurane were serially measured. Subjects were monitored for heart rate, blood pressure, and any procedural complications.

Results: None of the patients experienced any episodes of hypoxia, hypercapnia, and arrhythmia in both groups. The maximal end-tidal $\mathrm{CO}_{2}$ was $40.9 \pm 3.9 \mathrm{mmHg}$ in LFA and $38.2 \pm 3.6 \mathrm{mmHg}$ in $\mathrm{HFA}$, respectively. The minimal $\mathrm{O}_{2}$ saturation was $98.3 \pm 0.6 \%$ in LFA and $98.8 \pm 0.7 \%$ in HFA, respectively. The inspiratory $\mathrm{CO}_{2}$ concentrations in both groups were all less than $1 \mathrm{mmHg}$ throughout the anesthesia.

Conclusions: In conclusion, LFA with sevoflurane using FGF of $1 \mathrm{~L} / \mathrm{min}$ with setting of $50 \% \mathrm{O}_{2}$ and $\mathrm{N}_{2} \mathrm{O}$ for LC could be performed safely without the risk of complications like hypercapnia, hypoxia, or arrhythmia compared to HFA. (Korean $\mathbf{J}$ Anesthesiol 2005; 49: S 1 5)

Key Words: fresh gas flow, laparoscopy, sevoflurane.

\section{INTRODUCTION}

There has been a revival of interest in low-flow anesthesia (LFA) techniques over the past decade or so, primarily driven by the introduction of newer anesthetic agents with low solubility and relatively higher costs. The advantages of LFA include a reduction in the consumption of anesthetic gases, reduced operating room and environmental pollution, and the conservation of heat and humidity within the respiratory tract of patients. ${ }^{1-3)}$ Historically, most anesthesiologists have been trained to use high-flow anesthesia (HFA), and the anesthetic equipment and available anesthetic agents have not been suitable for LFA. HFA techniques, however, have the potential for inducing hypoxia and/or hypercapnia, administration of an over- or underdosage of anesthetic gases, and the accumulation of potentially toxic degradation

Received : June 26, 2005

Corresponding to : Young Ho Jang, Department of Anesthesiology and Pain Medicine, School of Medicine, Keimyung University, 194 Dongsan-dong, Jung-gu, Daegu 700-712, Korea. Tel: 82-53-250-7287, Fax: 82-53-250-7240, E-mail: weonjo@dsmc.or.kr products. $^{4-7)}$

Laparoscopic cholecystectomy (LC) with intra-abdominal $\mathrm{CO}_{2}$ insufflation has a special anesthetic consideration in that it may induce hypercapnia, acidemia, and depressed hemodynamics. ${ }^{8)}$ A number of studies have been published evaluating the use of LFA in a wide variety of surgical procedures, including gastrointestinal, gynechological and general surgery. ${ }^{9-11)}$ Despite many advantages of the LFA as mentioned above, few studies have actually been done using LFA with sevoflurane in LC. One likely explanation is the potential for hypercapnia with LFA resulting from rebreathing exhaled $\mathrm{CO}_{2}$ coupled with an increase in arterial $\mathrm{CO}_{2}$ from the intraperitoneal $\mathrm{CO}_{2}$ insufflation.

The purpose of this study was to investigate whether the LFA is safe and compatible with the $\mathrm{LC}$ involving abdominal $\mathrm{CO}_{2}$ insufflation.

\section{MATERIALS AND METHODS}

After obtaining Institutional Review Board approval and written informed consent from each patient, 80 patients, ASA I or II status, who were to undergo elective LC under general anesthesia were 
Table 1. Patient Demographics

\begin{tabular}{lcc}
\hline & $\begin{array}{c}\text { LFA } \\
(\mathrm{n}=40)\end{array}$ & $\begin{array}{c}\text { HFA } \\
(\mathrm{n}=40)\end{array}$ \\
\hline Age $(\mathrm{yr})$ & $50.0 \pm 11.5$ & $48.9 \pm 12.3$ \\
Sex $(\mathrm{m} / \mathrm{f})$ & $18 / 22$ & $20 / 20$ \\
Weight $(\mathrm{kg})$ & $64.8 \pm 9.5$ & $61.9 \pm 10.4$ \\
Anesthetic duration (min) & $67.0 \pm 11.3$ & $70.4 \pm 12.3$ \\
\hline
\end{tabular}

Data are mean \pm SD except sex (number). LFA: low-flow anesthesia, HFA: high-flow anesthesia.

enrolled. The patients were randomly assigned to one of two groups, LFA or HFA ( $n=40$ in each group), depending on fresh gas flow (FGF) settings. Patients with cardiopulmonary disease, previous adverse reactions to inhaled agents, intravenous anesthesia, obesity, smoking history, and where the procedure was subsequently changed to open cholecystectomy were excluded from the study. Age, gender, and weight were recorded for all subjects. There was no statistically difference in patient demographics (including age, gender, weight, and anesthetic duration) between the two groups (Table 1).

All anesthetic procedures were performed by one of the two authors, who was experienced in the application of the LFA. All patients were premedicated with midazolam ( $7.5 \mathrm{mg}$ orally), the night before the operation, and intramuscular 2-2.5 $\mathrm{mg}$ midazolam and $0.2 \mathrm{mg}$ glycopyrrolate, $30 \mathrm{~min}$ before entering the operating room (OR).

After arrival in the OR, baseline hemodynamic parameters were recorded after a $5 \mathrm{~min}$ stabilization period on the operating table. Before anesthetic induction, all patients breathed $100 \% \mathrm{O}_{2}$ for 3 min, FGF $6 \mathrm{~L} / \mathrm{min}$, using a face mask connected to a semiclosed breathing circuit (Datex Ohmeda 7,000 ventilator, Datex-Ohmeda, USA). After preoxygenation, $2 \mathrm{mg} / \mathrm{kg}$ propofol, $0.6 \mathrm{mg} / \mathrm{kg}$ rocuronium bromide, and $1-2 \mu \mathrm{g} / \mathrm{kg}$ fentanyl were administered intravenously. Tracheal intubation was followed by mechanical ventilation with a tidal volume of $10 \mathrm{ml} / \mathrm{kg}$ at 10 breaths $/ \mathrm{min}$. Inspiratory/expiratory ratio was set as $1: 2$. These respiratory parameters were not modified during the procedures. All procedures were performed using the same circle breathing system and vaporizer (Vapor 2000, Drager, Germany) with sevoflurane under standard operating room conditions. The accuracy of the flowmeters was verified by passing the FGF through a dry gas meter (Parkinson-Cowan, Birmingham, UK).

Lead II of an electrocardiogram on the patient's back and saturation via pulse oximetry $\left(\mathrm{SpO}_{2}\right)$ at patient's finger were con- tinuously monitored. An automated blood pressure cuff was applied to the right arm. To ensure uniform conditions, same patient monitoring equipment was used in all cases. Electrocardiography, oscillatory blood pressure, and pulse oximetry was monitored using Agilent M1205A (Agilent technologies Co., Germany). Peak airway pressure was measured using anesthesia machine (Datex Ohmeda 7,000 ventilator, Datex-Ohmeda, USA). Tidal volume and minute ventilation were measured using 5420 volume monitor (Ohmeda, USA). We also serially measured inspiratory and expiratory fractional concentrations of the $\mathrm{O}_{2}, \mathrm{~N}_{2} \mathrm{O}$, $\mathrm{CO}_{2}$, and sevoflurane using a multi-gas monitor (Capnomac Ultima, Datex-Ohmeda, Finland). The accuracy of multi-gas monitor was tested before the study (accuracy for $\pm 10 \%$ ). Fresh soda lime (Sodasorb ${ }^{\circledR}$, W.R. Grace \& Company, USA) was used during each individual anesthesia procedure.

Variables were measured immediately prior to $\mathrm{CO}_{2}$ pneumoperitoneum and every 5 minutes thereafter until the end of surgery but were presented 10 (T1), 20 (T2), 30 (T3) minutes after $\mathrm{CO}_{2}$ pneumoperitoneum and immediately before emergence from anesthesia (T4). Neuromuscular transmission was monitored by train-of-four stimulation (TOF Watch, Organon Teknika, Netherlands).

After tracheal intubation, $\mathrm{O}_{2}$ and $\mathrm{N}_{2} \mathrm{O}$ flow was $2 \mathrm{~L} / \mathrm{min}$ and 2 L/min, respectively. These parameters were maintained throughout the duration of anesthesia in HFA group. The initial inspiratory sevoflurane concentration was $2.6 \mathrm{vol} \%$ in HFA group. In LFA group, initial FGF was $4.5 \mathrm{~L} / \mathrm{min}, 1.5 \mathrm{~L} / \mathrm{min} \mathrm{O}_{2}$ and 3.0 $\mathrm{L} / \mathrm{min} \mathrm{N}_{2} \mathrm{O}$, and an inspiratory sevoflurane concentration was 2.6 vol\%. This initial high flow phase lasted $10 \mathrm{~min}$ to allow for initial rapid uptake of $\mathrm{N}_{2} \mathrm{O}$ and elimination of nitrogen. Thereafter, FGF was reduced to $1 \mathrm{~L} / \mathrm{min}, 500 \mathrm{ml} / \min \mathrm{O}_{2}$ and $500 \mathrm{ml} / \mathrm{min} \mathrm{N}_{2} \mathrm{O}$, and the vaporizer dial of sevoflurane was set at 3.0 vol\%. During the $\mathrm{CO}_{2}$ pneumoperitoneum, the intra-abdominal pressure was maintained between 12 and $15 \mathrm{mmHg}$ by $\mathrm{CO}_{2}$ insufflator.

In both groups, sevoflurane concentration was adjusted throughout the anesthesia to maintain systemic arterial blood pressure and heart rate (HR) within $\pm 30 \%$ of baseline values. Light anesthesia was defined as tachycardia (HR $>+30 \%$ of baseline values or HR $>110$ beats/min) or hypertension (mean arterial pressure [MAP] $>+30 \%$ of baseline values or MAP $>100 \mathrm{mmHg}$ ). The occurrence of hypoxia and hypercapnia was noted throughout the anesthesia. Hypoxia and hypercapnia were defined as $\mathrm{SpO}_{2}$ less than $90 \%$ and end- tidal $\mathrm{CO}_{2}\left(\mathrm{ETCO}_{2}\right)$ more than $50 \mathrm{mmHg}$, respectively.

Whenever the inspiratory concentration of $\mathrm{O}_{2}$ was noted to be 
low $30 \%, \mathrm{O}_{2}$ flow was increased by $10 \%$ of the total FGF, while reducing the $\mathrm{N}_{2} \mathrm{O}$ flow by the same amount. At the end of surgery, the vaporizer dial of sevoflurane was turned off and the $\mathrm{O}_{2}$ flow was increased to $6 \mathrm{~L} / \mathrm{min}$ along with discontinuation of $\mathrm{N}_{2} \mathrm{O}$ administration. Residual neuromuscular block was antagonized at the start of skin closure by the administration of pyridostigmine and glycopyrrolate. Patients were extubated upon awakening.

Prior to the study, a power analysis was performed to determine population size based on the $3 \%$ incidence of hypercapnia during $\mathrm{CO}_{2}$ pneumoperitoneum as reported by Qureshi EA. ${ }^{12)}$ We presumed that a $\pm 10 \%$ incidence of hypercapnia in LFA group would be as effective and safe as the HFA group. This required recruitment of 36 patients in each group, as noted above.

Data was presented as mean \pm standard deviation (SD). Data analysis was performed using the SPSS statistical Package program version 11.0 (SPSS Inc., Chicago, USA). Statistical analysis for demographics, maximal $\mathrm{ETCO}_{2}$, and minimal $\mathrm{SpO}_{2}$ was done by using independent sample t-test. We used GLM (General Linear Model) repeated measures procedures to analyze the changes in hemodynamics and concentrations of $\mathrm{O}_{2}, \mathrm{~N}_{2} \mathrm{O}, \mathrm{CO}_{2}$ and sevoflurane between two groups. Statistical significance was set at five percent level.

\section{RESULTS}

Maximal $\mathrm{ETCO}_{2}$ was $40.9 \pm 3.9 \mathrm{mmHg}$ in LFA group and 38.2 $\pm 3.6 \mathrm{mmHg}$ in HFA group. The minimal $\mathrm{SpO}_{2}$ was $98.3 \pm 0.6 \%$ (range 97-100\%) in LFA group and $98.8 \pm 0.7 \%$ (range 98$100 \%)$ in HFA group ( $\mathrm{P}=0.005)$. In both groups, the inspiratory $\mathrm{O}_{2}$ concentration never dropped below $30 \%$ on the multi-gas monitor. None of the patients experienced episodes of hypoxia, hypercapnia, and arrhythmia requiring treatment in either group.

The changes in concentration of gases are presented in Table 2. The inspiratory $\mathrm{O}_{2}$ concentrations were significantly lower in LFA group than in HFA group at $\mathrm{T} 1$ and $\mathrm{T} 2(\mathrm{P}=0.004)$. There were no statistical differences in inspiratory $\mathrm{O}_{2}$ concentrations at T3 and T4 between two groups. The inspiratory $\mathrm{N}_{2} \mathrm{O}$ concentrations in LFA group were significantly higher in LFA group than in HFA group at T1, T2, and T3 $(\mathrm{P}=0.007,0.003$ and 0.001 , respectively).

The inspiratory $\mathrm{CO}_{2}$ concentration in LFA group was significantly higher than in HFA group at $\mathrm{T} 1(\mathrm{P}=0.032)$. However, the inspiratory $\mathrm{CO}_{2}$ concentrations in both groups were all less than 1 $\mathrm{mmHg}$ throughout the duration of anesthesia. The $\mathrm{ETCO}_{2}$ in LFA group were significantly higher in LFA group than in HFA group at $\mathrm{T} 1, \mathrm{~T} 3$, and $\mathrm{T} 4(\mathrm{P}=0.016,0.000$ and 0.000$)$. The highest

Table 2. Changes in Inspiratory and Expiratory Gases during $\mathrm{CO}_{2}$ Pneumoperitoneum

\begin{tabular}{|c|c|c|c|c|c|}
\hline & & $\mathrm{T} 1$ & $\mathrm{~T} 2$ & $\mathrm{~T} 3$ & $\mathrm{~T} 4$ \\
\hline \multirow[t]{2}{*}{ Ins- $\mathrm{O}_{2}(\%)$} & LFA & $42.0 \pm 11.0^{*}$ & $46.8 \pm 4.6^{*}$ & $47.7 \pm 2.6$ & $47.8 \pm 2.4$ \\
\hline & HFA & $49.5 \pm 7.9$ & $50.2 \pm 4.1$ & $49.4 \pm 4.3$ & $49.3 \pm 5.6$ \\
\hline \multirow[t]{2}{*}{ Exp- $\mathrm{O}_{2}(\%)$} & LFA & $40.3 \pm 11.4^{*}$ & $43.1 \pm 5.3^{*}$ & $43.6 \pm 2.9^{*}$ & $43.7 \pm 2.1$ \\
\hline & HFA & $47.5 \pm 7.4$ & $47.1 \pm 2.4$ & $46.6 \pm 1.8$ & $46.3 \pm 1.8$ \\
\hline \multirow[t]{2}{*}{ Ins- $\mathrm{N}_{2} \mathrm{O}(\%)$} & LFA & $53.4 \pm 10.4^{*}$ & $49.1 \pm 4.4^{*}$ & $48.4 \pm 2.6^{*}$ & $48.0 \pm 2.5$ \\
\hline & HFA & $47.3 \pm 5.7$ & $46.4 \pm 1.0$ & $46.5 \pm 1.1$ & $47.1 \pm 1.6$ \\
\hline \multirow[t]{2}{*}{ Exp- $\mathrm{N}_{2} \mathrm{O}(\%)$} & LFA & $51.0 \pm 10.6^{*}$ & $48.0 \pm 4.9^{*}$ & $47.2 \pm 2.7^{*}$ & $47.2 \pm 1.9^{*}$ \\
\hline & HFA & $44.9 \pm 6.0$ & $45.1 \pm 1.1$ & $45.3 \pm 1.1$ & $45.6 \pm 1.1$ \\
\hline \multirow[t]{2}{*}{ Ins- $\mathrm{CO}_{2}(\mathrm{mmHg})$} & LFA & $0.5 \pm 0.5^{*}$ & $0.2 \pm 0.4$ & $0.4 \pm 0.5$ & $0.4 \pm 0.5$ \\
\hline & HFA & $0.2 \pm 0.4$ & $0.1 \pm 0.4$ & $0.2 \pm 0.4$ & $0.3 \pm 0.5$ \\
\hline \multirow[t]{2}{*}{ Exp- $\mathrm{CO}_{2}(\mathrm{mmHg})$} & LFA & $32.6 \pm 3.9^{*}$ & $35.6 \pm 4.8$ & $40.0 \pm 4.1^{*}$ & $41.1 \pm 3.5^{*}$ \\
\hline & HFA & $29.4 \pm 6.0$ & $33.7 \pm 4.2$ & $36.1 \pm 3.3$ & $36.8 \pm 3.0$ \\
\hline \multirow[t]{2}{*}{ Ins-Sevo (vol\%) } & LFA & $2.0 \pm 0.4^{*}$ & $2.0 \pm 0.4^{*}$ & $2.1 \pm 0.3^{*}$ & $2.2 \pm 0.2$ \\
\hline & HFA & $2.3 \pm 0.3$ & $2.4 \pm 0.5$ & $2.3 \pm 0.3$ & $2.4 \pm 0.3$ \\
\hline \multirow[t]{2}{*}{ Exp-Sevo (vol\%) } & LFA & $1.7 \pm 0.3^{*}$ & $1.7 \pm 0.3^{*}$ & $1.9 \pm 0.3^{*}$ & $1.8 \pm 0.2^{*}$ \\
\hline & HFA & $1.9 \pm 0.4$ & $2.1 \pm 0.4$ & $2.0 \pm 0.3$ & $2.0 \pm 0.3$ \\
\hline
\end{tabular}

Values are mean \pm SD. LFA: low-flow anesthesia, HFA: high-flow anesthesia, Ins: inspiration, Exp: expiration, Sevo: sevoflurane. T1, T2, and T3: 10, 20, and 30 minutes after carbon dioxide pneumoperitoneum, T4: immediately before emergence of anesthesia. *: P $<0.05$ compared to HFA. 
$\mathrm{ETCO}_{2}$ level was observed at T4 in both groups. The inspiratory and expiratory sevoflurane concentrations were lower in LFA group than in HFA group throughout the duration of anesthesia ( $P$ $<0.05)$.

\section{DISCUSSION}

The LFA was first introduced by Foldes et al. ${ }^{13)}$ in 1952. Since then, the technique has been variously defined by different authors. ${ }^{1,14)}$ The purpose of this study was to examine the efficacy of LFA with sevoflurane in $\mathrm{LC}$ with $\mathrm{CO}_{2}$ pneumoperitoneum.

Traditionally, anesthetists participating in LC have been quite cautious about adapting LFA due to the potential for inducing hypoxia, hypercapnia, and accumulation of toxic degradation products such as compound $\mathrm{A}$ by sevoflurane due to the exhaled $\mathrm{CO}_{2}$ rebreathing and administration of small amount of oxygen less than $500 \mathrm{ml} / \mathrm{min}^{4-7)}$ However, it has several benefits, including the reduced consumption of anesthetic gases, reduced environmental pollution, and conservation of heat and humidity within the respiratory tract. $^{1-3)}$

In the present study, a semiclosed-circuit with a soda lime absorbent was used as the $\mathrm{CO}_{2}$ absorbent. All our patients were operated as the first case of the day. Therefore, the fresh soda lime absorbent was used during each anesthesia. The inspiratory $\mathrm{CO}_{2}$ concentrations in LFA and HFA groups were less than $1 \mathrm{mmHg}$ throughout the anesthesia and there in no case did the $\mathrm{ETCO}_{2}$ increase more than $50 \mathrm{mmHg}$ in LFA group. The duration of anesthesia was short in all our patients (mean 67.0 min in LFA and $70.4 \mathrm{~min}$ in HFA). These findings suggest that the clinically significant $\mathrm{CO}_{2}$ rebreathing is not developed in patients undergoing $\mathrm{LC}$ with a brief period of anesthesia with intraperitoneal $\mathrm{CO}_{2}$ insufflation if fresh soda lime is used in the circuit.

One another important barrier to LFA acceptance is the possibility of hypoxia resulting from inspiration of low $\mathrm{O}_{2}$ concentrations during rebreathing. This may be one of the major disadvantages associated with the use of LFA. In our present study, the minimal $\mathrm{SpO}_{2}$ in LFA group was $98.3 \pm 0.6 \%$ and this result was similar to that of HFA group $(98.8 \pm 0.7 \%)$, although it was noted to be statistically significant. No patients experienced hypoxia defined as decrease in $\mathrm{SpO}_{2}$ less than $90 \%$ in the LFA group.

Sajedi et al. ${ }^{15)}$ reported that the LFA could be used with relative safety in anesthetic $\mathrm{m}$ anagement of patients during LC. However, they used halothane as an inhalation agent. Sevoflurane has a number of properties that allow for the full realisation of the benefits of LFA. The lower solubility of sevoflurane compared to halothane results in more rapid alveolar equilibration and tissue elimination, and this property is particularly well suited for use during LFA. However, the potentially toxic degradation products may be accumulated during the LFA with sevoflurane. ${ }^{16)}$ The flow rate is one of the most important factors in determining the rate at which Compound $\mathrm{A}$ is produced. Although we did not directly check the Compound A concentrations in our present study, none of our patients revealed any postoperative renal dysfunction clinically significant or postoperative blood urea nitrogen concentrations that would suggest potentially toxic Compound A production.

We presumed the hypercapnia as $\mathrm{ETCO}_{2}$ without direct checking the arterial $\mathrm{CO}_{2}$ tension $\left(\mathrm{PaCO}_{2}\right)$. The diversity has been shown between $\mathrm{PaCO}_{2}$ and $\mathrm{ETCO}_{2}$ during LC. ${ }^{17)}$ However, BhavaniShankar et al. ${ }^{18)}$ demonstrated that the difference between $\mathrm{PaCO}_{2}$ and $\mathrm{ETCO}_{2}$ was only $2.6 \pm 1.2 \mathrm{mmHg}$ during $\mathrm{CO}_{2}$ pneumoperitoneum in 8 pregnant women undergoing LC. They concluded that capnography is adequate to measure $\mathrm{CO}_{2}$ status and to guide ventilation during laparoscopic surgery. This was our justification not to directly measure $\mathrm{PaCO}_{2}$ in our patients.

In conclusion, LFA with sevoflurane using FGF of $1 \mathrm{~L} / \mathrm{min}$ with setting of $50 \% \mathrm{O}_{2}$ and $\mathrm{N}_{2} \mathrm{O}$ for LC is safe without any significant likelihood of risks such as hypercapnia, hypoxia, and arrhythmia.

\section{REFERENCES}

1. Baum JA, Aitkenhead AR: Low-flow anaesthesia. Anaesthesia 1995; 50: S37-44.

2. Imberti R, Preseglio I, Imbriani M, Ghittori S, Cimino F, Mapelli A, et al: Low flow anaesthesia reduces occupational exposure to inhalation anaesthetics: environmental and biological measurements in operating room personnel. Acta Anaesthesiol Scand 1995; 39: 586-91.

3. Kleemann PP: Humidity of anaesthetic gases with respect to low flow anaesthesia. Anaesth Intensive Care 1994; 22: 396-408.

4. Liu J, Laster MJ, Eger EI 2nd, Taheri S: Absorption and degradation of sevoflurane and isoflurane in a conventional anesthetic circuit. Anesth Analg 1991; 72: 785-9.

5. Hargasser S, Hipp R, Breinbauer B, Mielke L, Entholzner E, Rust $\mathrm{M}$, et al: A lower solubility recommends the use of desflurane more than isoflurane, halothane, and enflurane under low-flow conditions. J Clin Anesth 1995; 7: 49-53.

6. Aldrete JA: Compound A concentrations during sevoflurane anesthesia in children depend on fresh gas flow. Anesthesiology 1996; 85: 684 .

7. Meakin GH: Low-flow anaesthesia in infants and children. Br J Anaesth 1999; 83: 50-7. 
8. Holzman M, Sharp K, Richards W: Hypercarbia during carbon dioxide gas insufflation for therapeutic laparoscopy: a note of caution. Surg Laparosc Endosc 1992; 2: 11-4.

9. Bito H, Ikeda K: Closed-circuit anesthesia with sevoflurane in humans. Effects on renal and hepatic function and concentrations of breakdown products with soda lime in the circuit. Anesthesiology 1994; 80: 71-6.

10. Bito H, Ikeda K: Degradation products of sevoflurane during lowflow anaesthesia. Br J Anaesth 1995; 74: 56-9.

11. Lu CC, Ho ST, Wang JJ, Wong CS, Tsai CS, Chang SY, et al: Minimal low-flow isoflurane-based anesthesia benefits patients undergoing coronary revascularization via preventing hyperglycemia and maintaining metabolic homeostasis. Acta Anaesthesiol Sin 2003; 41: 165-72.

12. Qureshi FA: Anesthesia related complications of laparoscopic cholecystectomy. J Coll Physicians Surg Pak 2003; 13: 369-71.

13. Foldes FF, Ceravolo AJ, Carpenter SL: The administration of nitrous oxide-oxygen anesthesia in closed systems. Ann Surg 1952;
136: $978-81$.

14. Gregorini P: Effect of low fresh gas flow rates on inspired gas composition in a circle absorber system. J Clin Anesth 1992; 4: 439-43.

15. Sajedi P, Naghibi K, Soltani H, Amoshahi A: A randomized, prospective comparison of end-tidal $\mathrm{CO}_{2}$ pressure during laparoscopic cholecystectomy in low and high flow anesthetic system. Acta Anaesthesiol Sin 2003; 41: 3-5.

16. Morio M, Fujii K, Satoh N, Imai M, Kawakami U, Mizuno T, et al: Reaction of sevoflurane and its degradation products with soda lime. Toxicity of the byproducts. Anesthesiology 1992; 77 : 1155-64.

17. Bures E, Fusciardi J, Lanquetot H, Dhoste K, Richer JP, Lacoste L, et al: Ventilatory effects of laparoscopic cholecystectomy. Acta Anaesthetiol Scand 1996; 40: 566-73.

18. Bhavani-Shankar K, Steinbrook RA, Brooks DC, Datta S: Arterial to end-tidal carbon dioxide pressure difference during laparoscopic surgery in pregnancy. Anesthesiology 2000; 93: 370-3. 